\title{
Minding the gap: the professionals' view on the interaction between urban design theory and practice
}

\section{Hooman Foroughmand Araabi}

Senior Lecturer in Urban Planning and Design

Faculty of Environment and Technology (FET)

\begin{abstract}
In order to better understand the relationship between the theory and the actual practice of urban design, this paper identifies and analyses the key factors that are involved in generating new theories and practices. The discussion starts by reviewing the different traditions that have been key in the formation of urban design. The gap between theory and practice in urban design is then explored, followed by the ways in which a number of successful urban designers have experienced the tension between the two. The contribution is a new reading of the context of urban design capable of describing the profession.
\end{abstract}




\section{Introduction: Which theory and whose practice? The problem of differing conceptions}

In urban design, as in many other disciplines (Schon, 1984; Bernstein, 1972), there is a tension between theory and practice. Even though they are perceived to be distinct from each other, to a large extent, they both inform and form one another. In this respect, it is hard to pin down the precise meanings of theory and practice in the field. In addition, different methodologies (Carmona, 2014a) and varying models of theory used by urban designers (Foroughmand Araabi, 2017a) cause further complications as they insinuate that there are multiple variations of urban design. This suggests the possibility that the relationship between theory and practice can only be seen through the individuals' experience, without much commonality. After investigating what happens in reality, this paper shows that such a presumption is invalid and that the experiences of different professionals share certain specific characteristics.

The concept of theory is considered as abstract, complicated, academic and having generic meanings. On the other hand, practice is associated with being goal-oriented, untidy and fixed in location and time (Godfrey-Smith, 2003; Curd and Cover, 1998). Furthermore, the terms theory and practice often have different meanings in different contexts than those traditionally given to them. Key traditions that have played influential roles in the formation of the current perception of urban design are architecture, planning, sociology and philosophy (philosophy of art, philosophy of science and post-modern philosophy) (Larice and MacDonald, 2013; Gosling and Gosling, 2003; Lang, 2005). Each of these traditions has contributed to the process of generating new theories and practices of urban design. The paper first reviews the contributions of the traditions to urban design.

Many founders of urban design are either architects or planners. In fact, the discipline historically developed as a result of the discussion between planners and architects (Madanipour, 2014). From the architectural tradition, urban design accumulated ideas on how to envisage the physical form of cities (Le Corbusier, 1987; Giddens, 1984; Bacon, 1976; Spreiregen, 1965) and how to study the history of urban form in search of examples (Benevolo, 1980). From the perspective of the architectural tradition, urban design practice is a creative process giving physical form to public spaces and is mainly, if not solely, done by the designer. What architecture has contributed to the theory of urban design is harder to pin down, despite a few obvious examples (Venturi, 1977; Venturi et al., 2000; Chermayeff and Alexander, 1965; Le Corbusier, 1987).

Urban design has also taken much of its inspiration from town and urban planning. In particular, this includes many theoretical arguments, such as the idea of urban design being a process (Shirvani, 1985); the classification of theory into the descriptive and the prescriptive comes from discussions concerning planning (Faludi, 1986); and that most of the critical debates in urban design are also inspired by discussion in planning (Gunder, 2011; Foroughmand Araabi, 2017b). In this tradition, practice is closer to systematically following the procedure of decision-making and therefore the role of the designer becomes that of a collaborator and researcher.

Even though architecture and planning have substantially contributed to urban design, many key texts criticise both. For example, Jane Jacobs (1992) harshly criticised the main mode of urbanisation of her time. Christopher Alexander $(1965,1977)$ blamed architectural approaches in making urban environments. In this respect, one ironic way in which architecture and planning have been helpful to urban design is in providing theoretical material for criticism. Other disciplines have been constructive in analysing mainstream urban design and in finding alternatives approaches, especially sociological theories that pay particular attention to the spatial dimension of societies. The Chicago School of urban sociology provided one of the first of such theories that was followed by many sociologists in the last century (Tonkiss, 2005). Manifesting urban design theory as a way of understanding the social meaning of urban form (Castells, 1979; Cuthbert, 2007), studying people's behaviours (Gehl, 2011) and designing in accordance with everyday life (Lefebvre, 2011; Chase et al., 2008) are amongst the major contributions of sociology to the literature on urban design. Theory, from the perspective of

Page 2 of 16 
this tradition, is highly relevant to understanding the specific characteristics of a society and the ways in which it produces and adapts space. Theory is more descriptive than prescriptive. Practice is seen as embodying power and imposing a certain set of interests over others.

In addition to the traditions already mentioned, urban design's conception of theory and practice has, controversially, benefited from discussions about art. Although many urban designers, such as Jacobs, believed that urban design is not 'the work of art' (Jacobs, 1992), alternative conceptions of art, that are often more participatory, have been located at the core of urban design thinking (Bentley, 2002; Moughtin, 2003; Marshall, 2016). Art for urban design, and urban design as art, both present ways of deploying artistic traditions in the making of cities.

Another tradition that can be identified as having contributed to forming ideas of the theory and practice of urban design is that of scientific methodologies. Scientific methodologies brought about remarkable progress in the last century in various disciplines and many scholars employ them in their studies. Even if the disciplines do not fully fit into the category of scientific discourse, such methodologies were found to be helpful. Jacobs (1992) called for her theory to be tested using cities as laboratories, presumably utilising a scientific method. Scientific approaches are claimed to be valuable in understanding and controlling the contemporary city (Batty, 2013) and many urban design studies refer to scientifically-driven evidence in order to justify their findings (Ewing and Handy, 2009; Clifton et al., 2008; Badland and Schofield, 2005). In addition, there is a rich body of research in the philosophy of science with regard to the meaning and function of theory, a tradition which has helped the understanding of urban design. The classic way of defining theory from the perspective of the philosophy of science is used by Rowe and Koetter (1978). The more recent idea of a paradigm (Kuhn, 1996) has been adapted by Ellin (1999), Sternberg (2000) and Lang (2005), and Feyerabend's (2002) anarchist approach has inspired Cuthbert (2011). The mainstream practice of urban design, from this perspective, has been assessed to be pseudo-scientific as a result of not systematically testing theories (Marshall, 2012). Scientific methodology portrays the process of generating theory as a systematic deduction from a set of observations; in contrast, practice is the testing of theories in new contexts (Reynolds, 2007) and the problem of achieving this fully scientific portrait of urban design has been challenged (Dovey and Pafka, 2015).

Postmodernism has also been an influential tradition in the formation of what is called urban design. However, it is difficult, if not impossible, to define postmodernism. The broad arguments under the title of postmodernism have left urban design with a new understanding of its complexities (Venturi, 1977; Ellin, 1999), with connections between seemingly distinct aspects of the nature/built environment (MacHarg, 1992) and a critical view of power (Loukaitou-Sideris and Banerjee, 1998). From this perspective, urban design theory and practice are joint, yet complex and untidy activities that are inevitably related to other disciplines and sectors (Bentley, 1999).

Even though all the traditions studied have influenced the ways in which urban design theory and practice is formed, what happens in reality does not fully follow the models offered by those traditions. There are also other traditions and disciplines with less distinguishable influence on what is currently understood as urban design. History, cultural studies, big-data and computer science are several examples. Therefore, it is not possible through simple models to understand the mechanisms that generate the theory and practice of urban design. This is supported by the fact that neither theorists nor practitioners fully pursue any of the models in their own work. Therefore, in order to go beyond what these traditions portray, it is necessary to study the key factors involved in the production of theory and practice, focusing on real urban design. 


\section{Theory and practice; two sides of a gulf, staunch allies or complex synergies?}

Many scholars elaborate on the problem of the interaction between the theory and practice of urban design. Cuthbert believes that mainstream urban design theory is detached from the reality of social forces behind urban form (Cuthbert, 2005, 2007). Marshall (2012) argues that urban design theories are not being systematically evaluated, and thus have not methodologically evolved. Moudon states that the gap between theory and practice is 'hard to bridge' (Moudon, 1992). Even though these scholars often have different conceptions of urban design, different expectations of theory and different examples of urban design in mind, what they all highlight are the problematic connections between theory and practice. The question is, to what extent can the gap between the theory and practice of urban design argued by the professionals be attributed to their individual experience, and is there any common ground in this experience?

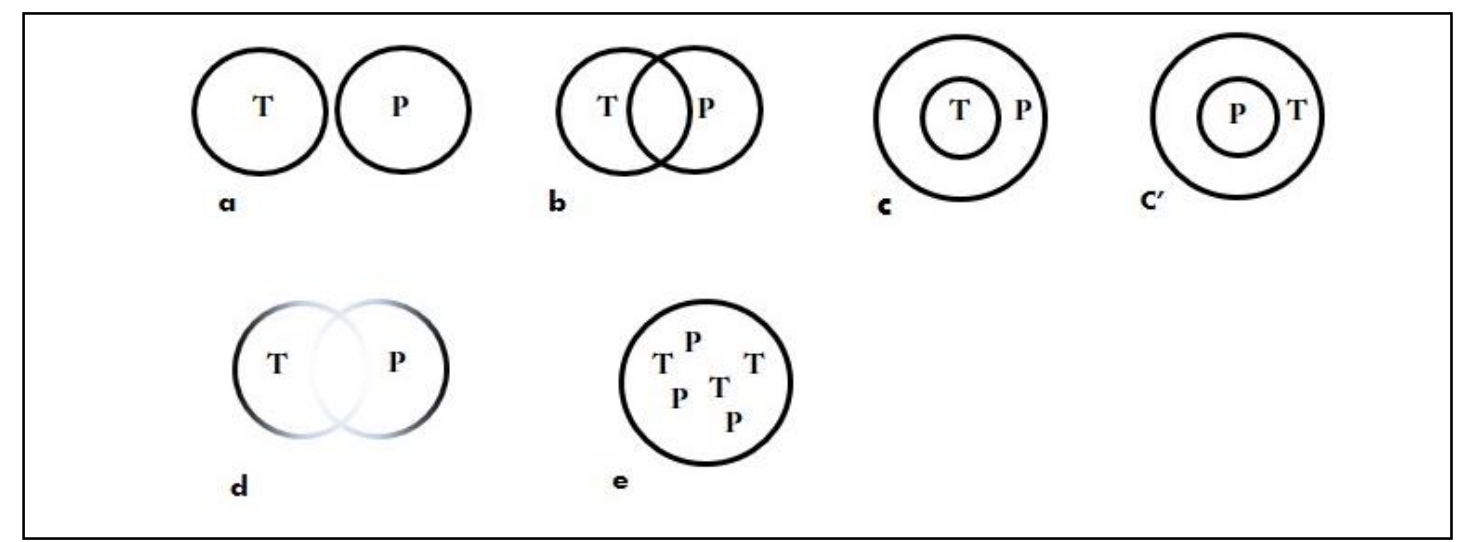

Figure 1 Five conceptual models of interactions between theory and practice: a) Theory and practice as distinguishable and distinct areas of activity; b) Distinguishable with overlapping areas; c) Practice is more comprehensive than theory; $c^{\prime}$ ) Theory more comprehensive than practice; d) Theory and practice hardy distinguishable but with different areas of concentration; e) Theory and practice not distinguishable

In general, it is possible to distinguish theory and practice, and think of academics and practitioners to represent them. The question remains, how are they located in relation to each other? Figure 1 shows five conceptual possibilities of the relationship between theory and practice. The logic for categorisation needs to clarify whether or not theory and practice have separate boundaries or overlap. When thinking of theory and practice as areas with solid boundaries, models $a, b, c$ and $c^{\prime}$ are applicable. When boundaries are less distinguishable, model $d$ applies. Finally, when there is no area of concentration for either theory or practice, model e is applicable. Despite the fact that different models could be applied to specific theories, it would be helpful to discover which model is closer to the reality of the field as a whole.

However, in the creation of new theory and practice, what is happening in reality is harder to grasp and more complicated than what is represented in Figure 1. There are other concepts involved; in fact, however helpful, one cannot fully picture the relationship between theory and practice through pure rational reasoning. Therefore, through investigations of the key factors that are identified by urban designers, this paper aims to portray a more comprehensive picture of the ways in which theory and practice interact.

The generation of theory and practice can be untidy and not formulaic; therefore, identifying and examining the key factors involved provides a better picture that can:

- help the future development of relevant knowledge;

- be used for educational purposes;

- aid better understanding between urban design and other disciplines; 
- develop a framework by which to analyse the role of those involved (individuals or institutes); and

- make new ways of revisiting urban design as a field in relation to other disciplines.

Aiming at providing a better understanding of what happens in reality, this paper identifies critical elements involved in the production of theory and practice from the perspective of key contributors.

\section{Identifying influential urban designers: Study participants}

The participants in this study are drawn from groups of theorists as well as practitioners. The list of theorists interviewed consists of writers whose texts appear in numerous university reading lists on urban design modules taken from a previous study (Foroughmand Araabi, 2016). Nine writers were interviewed, all of whom were involved with academia at a professorship level. Five were from the UK, two from the US and two from Australian universities.

The group of practitioners is a sample of those urban designers whose work appears inspiring to urban design academics, according to an online survey of urban design academics at University College London (UCL). A set of 13 interviews were conducted with these practitioners. Most of them are well known, have received awards and work in companies that are undertaking international projects. Two of the interviewees are from organisations involved in the promotion and establishment of urban design.

The respondents are all ideal representatives of the two groups who are actively creating the theory and practice of urban design. The interviews were semi-structured and tailor-made to the background of each interviewee. This allowed them to redefine the problems of the interaction between theory and practice through the perspective of their own experience. Therefore, the unique knowledge of each interviewee is examined.

\section{Common factors or concepts from the interviews}

From the interviews, a set of concepts appeared to be important in forming the context in which the interaction between theory and practice occurs. The fact that many concepts with comparable descriptions were repeated in the interviews implies that, in general, professionals share a similar understanding and experience. This finding affirms that there are shared understandings of analogous concepts amongst professionals. Most of these concepts comprise subjective factors that professionals use in order to explain how they work - to make sense of their experience. This is akin to what is defined as the function of a concept. Concepts help the human to make sense of the chaotic world (Deleuze and Guattari, 1994).

Despite the fact that set concepts are being repeated again and again in the interviews, in each interview these factors were framed and employed in a unique way. The similarities between them form the shared understanding of professionals. The process of giving understanding to these concepts makes their meaning and function more important than the actual words used. Consequently, in cases where one word was conceptualised in absolute terms, it was considered as potentially presenting two different concepts.

The concepts introduced below are all understood to be influential in the interaction between theory and practice but they have different functions, some broadening the gap between theory and practice and some lessening it. The common concepts in the interviews are as follows. 


\section{Government}

Governments and their policies directly influence the production of urban design in both academia and in practice. Most of the British interviewees emphasised the role of government and its influence on their work. The radical changes after the formation of the coalition government in 2010 in the UK and cuts in funding for design researchers and institutes raised awareness of the importance of government amongst urban designers. Thus, it could be claimed that, if a government does not change its policy for a long time, its influence would be less distinguishable. Enduring governmental policies should not result in an underestimation of their importance.

For academics, government finance for research was paramount. For the practitioners, government policies and projects were found to be more important. For both practitioners and academics, governmental support of institutions, such as the Commission for Architecture and the Built Environment (CABE), was crucial in making better interaction between theory and practice. The government's role was also discussed especially with relation to developing a network of professionals and supporting good design.

Governments have both widened and narrowed the gap between theory and practice on different occasions. Recent changes in cutting design budgets should therefore be seen in the bigger historical context. Four of the interviewees argued that urban design should attempt to be more independent from government. Making a judgment about this repeated claim falls outside of the scope of this research, but the government was evidently an important concern in the interviews.

\section{Personal choice}

The gap between theory and practice has been institutionally created. The ways in which universities develop knowledge does not exactly fit what is needed in practice. Other disciplines have different experiences. For example, this is radically different in the field of medicine, where theory and practice are strongly intertwined (Schon, 1984). In urban design, what practitioners do is not necessarily informed by the best and most recent research conducted in academia. On the other hand, practitioners repeatedly mentioned that academics are only interested in publishing academically rewarding pieces and do not understand the complexities of real projects.

Nevertheless, it appeared evident in the interviews that individuals have their own power and agency in interacting with the opposing group of professionals. Many successful practitioners and academics decided to find ways to benefit from such interaction. For academics, this often resulted in publications with more concrete examples that often interested young practitioners. Certain practitioners, in turn, have tried to access and absorb academic publications even though accessing journals is costly and reading them is time-consuming (mentioned by five practitioners). This type of interaction is not the dominant model for either group of professionals.

It is necessary to highlight here that the interviewees in this research had successfully made outstanding contributions to theory or practice and it could be expected that they would have a more than average tendency to interact with the other group. Unlike the first concept, this concept is in the hands of the professionals and they can improve the discipline by making greater efforts to inform and be informed about what happens on the other side of the gulf, even though this is not the norm in their working environment.

\section{Chance}

Many great contributions to both theory and practice have happened through unforeseen incidents. This has always been the case in the history of the progress of human knowledge; accidental events have a fundamental relationship with breakthroughs in knowledge (Feyerabend, 2002). 
Established processes produce expected outcomes but abnormalities in the processes can produce new outputs. In this respect, accident or chance has had an important impact on cases where theory and practice have had new ways to interact closely.

The interviewees referenced this concept in a wide variety of ways. Systematically analysing the element of chance in the interviews was not possible but the interviewees related: accidental meetings with other professionals; finding a text by chance; unexpectedly getting involved in projects; the accidental influence of their personal lives on professional achievements; and randomly choosing study programmes.

Nevertheless, an accident can only provide the opportunity. It is the individual who takes that opportunity and turns it into a success. Thus, their capacity in so doing should also be taken into account if chance is seen as a key element in the production of successful theory and practice.

\section{Education and professionalisation}

Throughout the interviews, education was repeatedly mentioned as being influential. In addition, many interviewees appeared to think that, through education, it is possible to lessen the gap between theory and practice.

By contrast, education was argued to cause the separation between the theory and practice of urban design and the 'uneasy relationship' between other disciplines and urban design. In particular, the point was made about the ways in which academia separated studies relating to the built environment into distinct disciplines, focusing excessively on specific issues without the ability to see the bigger picture. Both practitioners and academics who considered this were concerned with the complexity of the environment and the necessity of a more comprehensive view.

Fifty years ago, great designers were teaching at universities as well as designing inspiring buildings. This is becoming less and less the case. Then, urban design, architecture, planning and the design of an urban landscape were integrated; theory and practice were consequently closer to each other. The realisation of a built environment has developed a categorisation of professions and a bigger gap between theory and practice, as a by-product of such professionalisation, is inevitable.

More importantly, academia mostly appreciates achievements through its own media, such as peer-reviewed papers, funded-research and, more recently, Research Excellence Framework (REF) level publications. These criteria are not necessarily looking at existing problems in practice and do not guarantee a practical research outcome. Therefore, the educational environment is not fully linked to practice.

Nevertheless, by changing the understanding and expectations of the professional, the gap can be diminished in the future. Teaching improved knowledge and a better approach can be controlled more easily than, for example, government or chance, therefore making changes through education provides a feasible strategy for the profession.

\section{Clients}

Urban design projects and research often rely on the support of the client. This means both practitioners and academics are serving clients. In this respect, they cannot totally go against the client's will. Clients and professionals sometimes have different views about which approach to take. In an ideal situation, the support of a powerful client would allow the professionals to make outstanding contributions. But, in reality, professionals have to achieve agreements through lengthy negotiations. 
Many influential works would never have come into being without a client's generous support. The interviewees saw the tension between client and the professional as a limitation imposed on their ideal solutions. Four interviewees mentioned the opportunities for designers to educate their clients during their involvement. Whoever the client is, the designer needs to establish a mutual understanding of the value of design and research. This discussion raised the question of the extent to which negotiation skills should be taught as an academic part of urban design. Many interviewees believed that this influential skill needed improving.

\section{Developing projects without a client: Being proactive}

In some instances, outstanding contributions happened when the project was conducted independently. In other words, the project was developed before any engagement with the client. Later on, the clients became involved because of the perceived benefits of the project. This was a particular way of working with a client mentioned by six of the interviewees. Practitioners felt this to be inspiring and a better way of making their influence felt, as this method is more focused on the problem and less limited by regulations. It could be argued that this is atypical. Similarly, academics also sometimes work without funding.

This way of working, however, is not available to all professionals. Supposedly, such projects are time-consuming and costly; examples of practices that manage development in this way were often large companies that were able to manage these developments alongside their ongoing projects. Similarly, academics who were established enough and had time for independent projects are able to be proactive in this sense. Yet this concept highlights the fact that dealing with urban problems merely through regulated processes limits the opportunities to address them in innovative ways.

\section{Communication}

Urban design being a multidisciplinary field, communication is a fundamental skill for urban designers in disseminating ideas and working with other professionals. This comment appeared repeatedly in the interviews. The main purposes of communication were to find out about the newest skills and techniques, as well as knowing what projects their peers were undertaking. Many individuals expressed concerns about the lack of communication amongst their fellow professionals. Communication inevitably happens through a range of different channels, with the main channels mentioned being:

- events (including conferences, book launches, awards);

- academic and non-academic journals;

- universities;

- books;

- professional projects; and

- reports.

In general, communication only occurs when it is felt to be necessary as it is often time-consuming. From the interviews, it can be concluded that communication within groups of practitioners and groups of academics was stronger than communication between academics and practitioners. An additional complexity is that communication in an urban design environment is sometimes through visualisation. Communication, along with negotiation, can change the client's expectations, government regulations and ultimately the user's taste, but it will not be easy. 


\section{Site visiting}

Many academics and practitioners emphasised the fact that, for them, visiting good urban environments has always been a principal source of learning and helpful in developing their understanding. Accordingly, the existing built environment appears to be an important factor influencing the generation of theory and practice of urban design; good environments cannot be reduced to neither theory nor practice. Following on from this, different lessons can be achieved from the existing built environment based on the visitor's attitude. For example, in Space, Time and Architecture (2009), Giedion highlights the movement of space in Renaissance Italian cities and, later in his book, he extends this approach to support American highways. By contrast, the same Italian environments have been consistently referred to as glamorous examples of human scale in a smaller space (Moughtin, 2004; Tibbalds, 2000; Zucker, 1970). It appears that the built environment carries within itself a potential for various lessons.

Successful built environments are places in which theory and practice interface or even merge. If academia and practice were to cut their connection with the built environment, the gap between them would increase dramatically. Visiting successful sites inspires both practitioners and theorists and visiting bad environments has a similarly important influence. This inspiration is available to both novices and well-established professionals. Site visiting must be better incorporated into urban design programmes. Finding out that site visiting is an important factor implies that theory does not replace the experience that informed the theory. In the same way, one cannot put all the lessons from the built environment on paper or, at least, this has not happened yet.

\section{History}

Closely related to the concept of site visiting, many interviewees pointed out the importance of learning from history. For them, history is theory and practice at the same time. History is manifested not only in the built environment but also in a society's literature, visual history, collective history and social norms. Some of the interviewees think that it is possible to test new ideas against the lessons of history. It is impossible to think about history without theory (Fulbrook, 2002). In order to critically engage with the triangle of theory, history, practice it is important to go beyond the five mainstream frameworks of history in relation to urban design (i.e. chronologies, typologies, utopias, fragments and materialist theory) (Cuthbert, 2007a, 27). This resonates with the widely-cited statement "a theory is not a theory at all, until it has been used in practice over a considerable period of time" (Reade, 1987, 156). One academic interviewed took this a step further stating that "history is theory".

In many societies, taking action against history (historical environments and norms) raises resistance, thus history could be seen as a factor that, with a limited scope, affects the development of theory and practice. Despite the fact that history, in terms of factual events, is not changeable, it can be interpreted in different ways. The key questions here are: Which interpretation of history is being used? And which course of action does this interpretation support?

\section{Location}

The city in which professionals live directly impacts on their interaction with their peers. For example, in big cities, such as London, the dynamics of professionals have different characteristics than for those of smaller towns. Interviewees gave examples of increased access to knowledge and professional events in bigger cities compared to places where the professional community is more scattered, such as the north of Britain. Consequently, the interviewees expressed more of a sense of support in big cities where professionals were frequently meeting with "like-minded people".

The actual location of professionals forms their network. As was argued in the section on communication, it seems that conferences are fairly successful in gathering together professionals, 
sometimes from great distances. Some interviewees mentioned that clients are also affected by the culture of their region. In this respect, both the researcher and the practitioner are influenced by their location.

\section{Research}

In its general meaning, research is a key concept in the interaction between theory and practice. Traditionally, research is responsible for developing knowledge, and knowledge, ultimately, enhances the experience of cities. Therefore, it is not surprising to see that research appears to be an important concept.

Nine interviewees mentioned that research can lessen the gap between theory and practice. Nevertheless, what they mean by research varies significantly. Some expected research to devise an explanation of how design can achieve specific objectives, such as safety; some expect research to expand the understanding of cities; and some take a middle way and expect research to both expand knowledge and have practical applications. Research can be seen as a way to expand existing theories or be informative for new ones.

However, research does not happen in a vacuum. It needs funding and institutional support. At a time when governmental support is less available, academic research has the duty to lessen the gap between theory and practice. In fact, it needs to do more with less. Research can provide evidence that supports a certain practice.

The findings in relation to the previous two concepts (location and history) raise an important question about how the theory-practice mechanisms specific to each location should be reflected in research. Here, Pierre Bourdieu's philosophy, in particular his concepts of habitus, field and capital may help to explain how culture (as a form of capital) is produced and functions differently in various locations; with research seen as a social methodology used to understand field in relation to power (Grenfell, 2008). This example reveals the need for further research and theorisation of urban design in this area.

\section{A comprehensive view}

The reality of urban design that widens the gap between theory and practice cannot be easily changed. Hence, the consequences can be countered with various strategies. Establishing a comprehensive view has the potential, as mentioned by the interviewees, to lessen the gap generated by professionalisation. This is a concept that has traditionally ben advocated by academics (Alexander, 1965; Bacon, 1976; Tibbalds, 2000).

The professionalisation of related fields in the built environment gave the practitioners a focused theoretical debate about the need for a comprehensive framework. The interviewees called for a comprehensive view in different ways. Some regarded a comprehensive view as a necessity for an urban designer and cited it as a reason for their own success. They believed moving towards a more comprehensive view would lessen the gap between theory and practice in this respect. But how is this possible? One of the interviewees believes that built environment-related disciplines must start from big issues, such as urban problems at a city scale, then professionalised in specific issues, such as architecture, in postgraduate programmes. Another believed that a more philosophical understanding of cities and the nature of change proposed by professionals would make for a more comprehensive view. A retired professor argued that universities would not change their curricula and the nature of urban design theories should be turned into comprehensive theories that, in places, collaborate with historically-inherited social structures. 


\section{Orthodoxies of urban design}

Urban design is an applied field. Therefore, there is a demand for guidelines and how-to-do texts. This amplifies the potential for employing a solution without fully understanding the problem. A practitioner explained how the orthodoxy of urban design is preventing new thinking amongst his colleagues. One example given outlined the way in which the Garden City model is thought to be "the right answer" due to the large number of professionals enthusiastically advocating this model. Another example was the way in which some practitioners "mimic small European town centres" when designing new suburban settlements. In both examples, what the orthodoxy supports has been "taken too literally" and implemented without a fresh and full consideration of the actual problem in hand.

Furthermore, the same concept, manifested differently, appeared in interviews with a few academics. Having established a set of ideas as urban design orthodoxies, they not only broaden the gap between theory and practice, but also neutralise the effectiveness of urban design thinking.

\section{Distinct groups? Differences in the views of the practitioners and the theorists}

The identified concepts have key roles in linking professionals together. Both theorists and practitioners have pointed at similar concepts, albeit with differing importance and definitions.

History, education and professional orthodoxy are found to be more influential for theorists. Professional orthodoxy, criticised by the majority of the interviewees, plays an important role here too. It could be argued that professionals define their own stance in regard to the orthodoxy and the ways in which they criticise it.

Compared to theorists, practitioners have weaker agreement on key concepts. It is necessary to highlight that, due to the methodology taken for this research, the practitioners interviewed have made significant contributions to urban design. Therefore, it is not surprising that many of them cite developing projects without clients. It would be expected that, amongst mainstream practitioners, this idea is less commonplace.

Communication is important to both practitioners and theorists when they talk about the different groups or links between different disciplines, but they seem to be relatively satisfied with the communication within their own group, be they theorists or practitioners.

It is crucial to highlight that the role and perception of key concepts are dynamic and, if the same methodology was run in another context or at a different time, the outcome of the research might be different. Nevertheless, it can be assumed that some concepts are changing more slowly than others. History is one such concept that appears to be central in the network, yet its importance does not vary as quickly as, for example, government.

\section{Analysing the key concepts}

The concepts identified here are of a disparate nature. Some are factual (e.g. history), some are approaches taken by professionals (e.g. comprehensive view) and some are activities (e.g. site visiting). Yet many of them overlap and influence each other. However, together they can represent an understanding of the key elements involved in the interaction between the theory and practice of urban design from the perspective of the interviewees.

Echoing Anthony Giddens model of structures and individual agency (1984), these factors can be divided into three groups: first, those that belong to the bigger context in which urban design 
operates; those belonging to the domain of the profession; and those belonging to the individual domain. The latter ones can be more easily changed, but changes to the factors belonging to the profession and the context are, in turn, increasingly difficult.

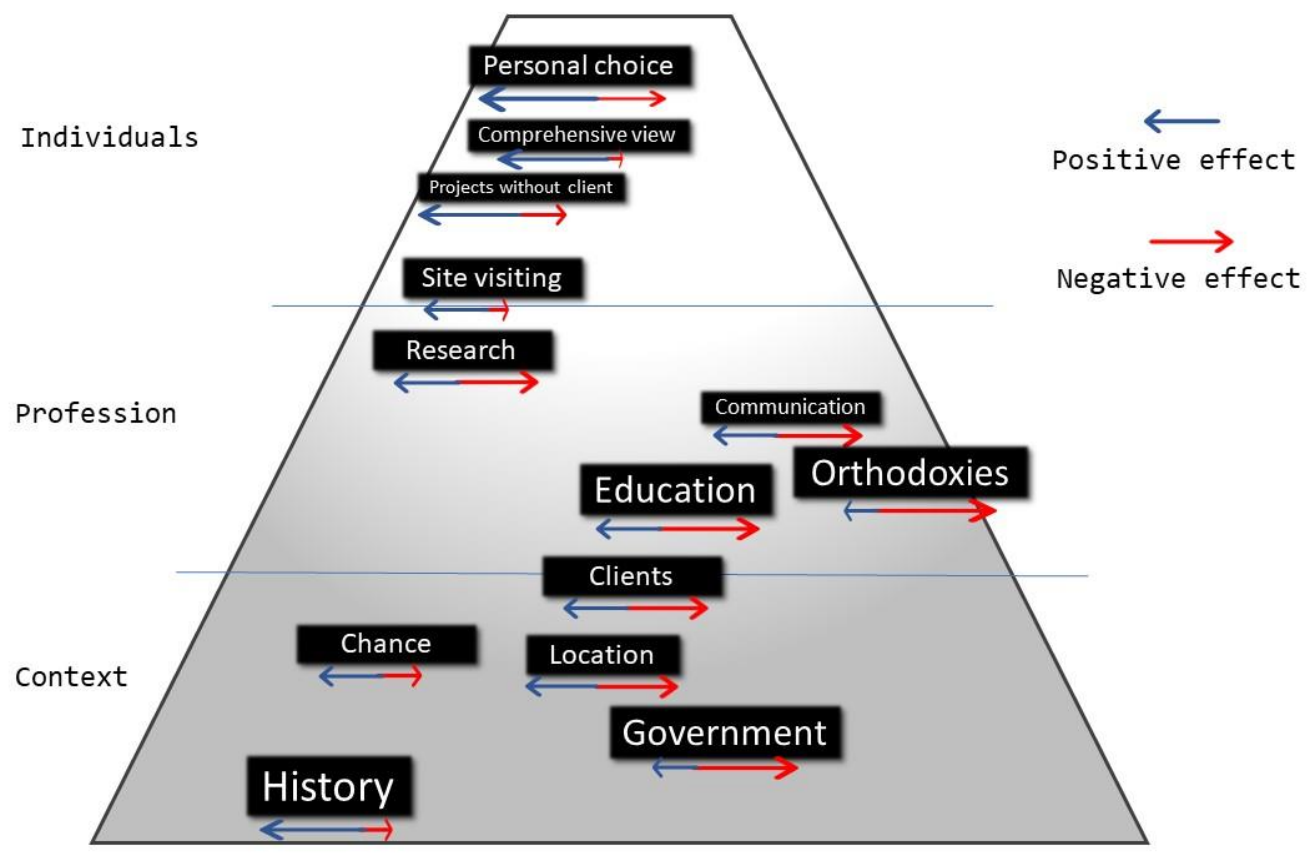

Figure 2 Identified factors divided into three categories of context, profession and individual domain. The factors also have positive and negative impacts on the gap between the theory and practice of urban design; the arrows depict their role as identified in the interviews. This diagram puts people and concepts with similar connections together.

Throughout the interviews, the identified factors were seen to have negative or positive influences on the interaction between theory and practice. Figure 2 illustrates the concepts in relation to the three spheres of context, profession and individual domains, as well as their positive and negative effects.

Comparing the findings of this research with Carmona's theory of urban design as place-shaping continuum (2014b), a well-received contribution that is currently the most-read paper in the Journal of Urban Design, reveals that interviewees were more involved with design and development. This means that making places through management and space in use are not the focal point of current successful urban designers.

\section{So, what is urban design after all?}

During the 1960s in America, urban design became an independent academic discipline (Krieger and Saunders, 2009). Nowadays, certain scholars picture it as a fairly independent area of research (Lang, 2005; Carmona, 2014a). Despite distinguished academic boundaries for urban design, practitioners are often involved in both architectural and planning projects. In a very few cases, they also conduct projects such as public art and community building and some of them have worked for other sectors such as CABE, RTPI and RIBA. Consequently, it could be concluded that practice of urban design is more integrated with other disciplines than its academic version. Understanding how influential urban designers explain the context in which they are working raises the question of what urban design is. This question has been repeatedly asked (Mumford, 2009; Krieger and Saunders, 2009; Gosling and Gosling, 2003). Yet the concept of urban design remains ambiguous, as Madanipour (1997) described two decades ago. The fact that this question has been asked again and again 
demonstrates that an adequate definition has still not been reached. Therefore, what has commonly been understood as key concepts can help to better describe urban design.

As Deleuze and Guattari (1994) explain, concepts help human beings make sense of the complexity of the chaotic outside world. The contribution of this paper is a description of the context of urban design through what professionals described as its key concepts. In this sense, urban design is an assemblage of these concepts, people, places, and relevant forces. The emphasis on site visiting and history endorses the necessity to see these elements together. Returning to what Figure 1 identified as various models of location theory and practice, model $d$ is closer to the reality described here. The need for further research was also highlighted through the interpretations of the interviews.

\section{Conclusion: Revisiting the question of the theory and practice gap}

Theory and practice are not entirely separate processes, and nor are the practitioners and theorists separate groups of people. In a larger context, they have similar aims, they move from one group to another, and there are few professionals who are both a practitioner and a theorist. This context can be best described by using the set of concepts they both identify and describe. Having a better understanding of these concepts would be helpful in making a better future for urban design.

There are processes in which theory and practice are not closely connected. From the interviews it is evident that knowledge is not passing seamlessly from one party to the other. Practitioners are busy developing their own knowledge that is situated, site-specific and practical. They are rarely interested in academic discussions, discourses, academic language and academic publications. However, they are keen to see new techniques. Academics, on the other hand, are often interested in achieving success through publications and citations that are not necessarily linked to real projects and practice. These groups have different ways of communicating. Academic language is formal and lengthy, whereas communication in practice is involved with visualisation, presentation and report-writing.

Theory and practice are generated through dynamic mechanisms. When professionals, both theorists and practitioners, face a blockage that cannot be solved by their existing understanding, they first doubt then reject the theory or practice in use. Additionally, when a new theory or technique becomes trendy, professionals are inclined to embrace it. The mechanisms for renewing an understanding are highly flexible. In the philosophy, science and history of knowledge, this process is considered to be anarchistic and opportunistic (Feyerabend, 2002). From the interviews, it could be concluded that there are not processes set up to generate new theories or practices. Nevertheless, studying key factors in the interaction between the theory and practice of urban design acknowledged the complexity and dynamic nature of the topic. This paper identified channels through which practitioners and theorists exchange knowledge. Nevertheless, communication is happening in an untidy way in the sense that it cannot be fully presented in any list of channels. In reality, professionals can make their own avenues for communication. They also adapt to new methods such as social media. Key channels are ways of transferring knowledge; the content transferred through them can vary from one professional to another. This, again, highlights the importance of considering findings at both a common level and an individual's level.

This research provided an understanding of the ways in which the theory and practice of urban design interact. The existing situation is understood differently by different individuals. For example, the interviewees have varying thoughts about the gap between theory and practice; some believed that the gap is decreasing as time passes, whilst another group believed that this gap has widened. Nevertheless, almost all of the interviewees believed that research and education are important solutions for lessening the divide.

The gap between theory and practice can be seen in the various experiences of different professionals. This research identified this gap and aimed to provide a better understanding of the 
interaction between theory and practice in order to make a contribution to this field of study. In so doing, a new way of describing urban design is provided in order to contribute to a better future for the profession.

\section{References}

Alexander, Christopher. 1965. 'A City Is Not a Tree'. Architectural Form 172.

- - - 1977. A Pattern Language: Towns, Buildings, Construction. New York: Oxford University Press. Bacon, Edmund N. 1976. Design of Cities. Rev. ed. A Penguin Book. New York: Penguin Books.

Badland, Hannah, and Grant Schofield. 2005. 'Transport, Urban Design, and Physical Activity: An Evidence-Based Update'. Transportation Research Part D: Transport and Environment 10 (3):177-96. https://doi.org/10.1016/j.trd.2004.12.001.

Batty, Michael. 2013. The New Science of Cities. Cambridge, Massachusetts: MIT Press.

Benevolo, Leonardo. 1980. The History of the City. 1st MIT Press ed. Cambridge, Mass: MIT Press.

Bentley, lan. 1999. Urban Transformations, Power, People and Urban Design. London: Routledge.

---. 2002. 'Urban Designers as Artists'. Urban Design International 7 (3-4):143-52. https://doi.org/10.1057/palgrave.udi.9000080.

Bernstein, Richard J. 1972. Praxis and Action: Contemporary Philosophies of Human Activity. Philadelphia: University of Pennsylvania Press. https://doi.org/10.9783/9780812205497.

Carmona, Matthew, ed. 2014a. Explorations in Urban Design: An Urban Design Research Primer. Farnham, Surrey, UK: Ashgate.

-- . 2014b. 'The Place-Shaping Continuum: A Theory of Urban Design Process'. Journal of Urban Design 19 (1):2-36. https://doi.org/10.1080/13574809.2013.854695.

Castells, Manuel. 1979. The Urban Question: A Marxist Approach. 1. MIT Press paperback ed. Cambridge, MA: MIT Press.

Chase, John, Margaret Crawford, and John Kaliski, eds. 2008. Everyday Urbanism. Expanded ed. New York: Monacelli Press.

Chermayeff, Serge, and Christopher Alexander. 1965. Community and Privacy; toward a New Architecture of Humanism. Garden City, N.Y.: Anchor Books.

Clifton, Kelly, Reid Ewing, Gerrit-Jan Knaap, and Yan Song. 2008. 'Quantitative Analysis of Urban Form: A Multidisciplinary Review'. Journal of Urbanism: International Research on Placemaking and Urban Sustainability 1 (1):17-45. https://doi.org/10.1080/17549170801903496.

Curd, Martin, and J.A Cover. 1998. Philosophy of Science the Central Issues. W.W.NOrton \& Company.

Cuthbert, Alexander. 2005. 'A Debate from Down-under: Spatial Political Economy and Urban Design'. URBAN DESIGN International 10:223-34.

- - . 2007a. The Form of Cities: Political Economy and Urban Design.

- - . 2007b. 'Urban Design: Requiem for an Era - Review and Critique of the Last 50 Years'. URBAN DESIGN International 12:177-223.

- - . 2011. Understanding Cities: Method in Urban Design. New York: Routledge.

Deleuze, Gilles, and Flix Guattari. 1994. What Is Philosophy? Translated by Graham. London: Verso.

Dovey, Kim, and Elek Pafka. 2015. 'The Science of Urban Design?' URBAN DESIGN International, December. https://doi.org/10.1057/udi.2015.28.

Ellin, Nan. 1999. Postmodern Urbanism. New York: Princeton architectural press.

Ewing, Reid, and Susan Handy. 2009. 'Measuring the Unmeasurable: Urban Design Qualities Related to Walkability'. Journal of Urban Design 14 (1):65-84. https://doi.org/10.1080/13574800802451155.

Faludi, A. 1986. Critical Rationalism and Planning Methodology. Pion Limited.

Feyerabend, Paul. 2002. Against Method. Verso.

Foroughmand Araabi, Hooman. 2016. 'A Typology of Urban Design Theories and Its Application to the Shared Body of Knowledge'. URBAN DESIGN International 21 (1):11-24. https://doi.org/10.1057/udi.2015.6. 
- - . 2017a. 'Multiple Expectations: Assessing the Assumed Roles of Theory in Relation to Urban Design'. Journal of Urban Design 22 (5):658-69. https://doi.org/10.1080/13574809.2017.1298402.

- - . 2017b. 'Schools and Skills of Critical Thinking for Urban Design'. Journal of Urban Design, September, 1-17. https://doi.org/10.1080/13574809.2017.1369874.

Fulbrook, Mary. 2002. Historical Theory. London; New York: Routledge.

Gehl, John. 2011. Life Between Buildings: Using Public Space. Vol. 6th. Island Press.

Giddens, Anthony. 1984. The Constitution of Society: Outline of the Theory of Structuration. Cambridge [Cambridgeshire]: Polity Press.

Godfrey-Smith, Peter. 2003. Theory and Reality an Introduction to the Philosophy of Science. Chicago; London: University of Chicago Press. http://site.ebrary.com/id/10395646.

Gosling, David, and Maria Cristina Gosling. 2003. The Evolution of American Urban Design. Wiley.

Grenfell, Michael, ed. 2008. Pierre Bourdieu: Key Concepts. Key Concepts. Stocksfield: Acumen.

Gunder, Michael. 2011. 'Commentary: Is Urban Design Still Urban Planning? An Exploration and Response'. Journal of Planning Education and Research 31 (2):184-195. https://doi.org/10.1177/0739456X10393358.

Jacobs, Jane. 1992. The Death and Life of Great American Cities. Vintage Books ed. New York: Vintage Books.

Krieger, Alex, and William S. Saunders, eds. 2009. Urban Design. Minneapolis: University of Minnesota Press.

Kuhn, Thomas S. 1996. The Structure of Scientific Revolutions. Chicago, IL: University of Chicago Press.

Lang, Jon T. 2005. Urban Design: A Typology of Procedures and Products. Oxford; Burlington, MA: Elsevier/Architectural Press.

Larice, Michael, and Elizabeth MacDonald, eds. 2013. The Urban Design Reader. Vol. Second. Routledge.

Le Corbusier. 1987. The City of To-Morrow and Its Planning. New York: Dover.

Lefebvre, Henri. 2011. The Production of Space. Translated by Donald Nicholson-Smith. Nachdr. Malden, Mass.: Blackwell.

Loukaitou-Sideris, Anastasia, and Tridib Banerjee. 1998. 'Postmodern Urban Form'. In Urban Design Reader, edited by Matthew Carmona and Steve Tiesdell, 42-51. Elsevier.

MacHarg, lan L. 1992. Design with Nature. 25th anniversary ed. New York: Wiley.

Madanipour, Ali. 2014. Urban Design, Space and Society. Planning, Environment, Cities. Basingstoke, Hampshire: Palgrave Macmillan.

Marshall, Stephen. 2012. 'Science, Pseudo-Science and Urban Design'. URBAN DESIGN International 17 (4):257-71. https://doi.org/10.1057/udi.2012.22.

- - . 2016. 'The Kind of Art Urban Design Is'. Journal of Urban Design, February, 1-25. https://doi.org/10.1080/13574809.2015.1133226.

Moudon, Anne Vernez. 1992. 'A Catholic Approach to Organizing What Urban Designers Should Know'. Journal of Planning Literature 6 (4):331-49.

Moughtin, Cliff. 2003. Urban Design: Method and Techniques. Architectural Press,.

- - - 2004. Urban Design: Street and Square. 3. ed., Repr. Amsterdam: Architectural Press.

Mumford, Eric. 2009. Defining Urban Design: CIAM Architects and the Formation of a Discipline, 193769. Yale University Press.

Reade, Eric. 1987. British Town and Country Planning. Milton Keynes, Buckinghamshire, England; Philadelphia: Open University Press.

Reynolds, Paul D. 2007. A Primer in Theory Construction. Allyn and Bacon Classics ed. Allyn and Bacon Classics. Boston: Pearson/AandB.

Rowe, Colin, and Fred Koetter. 1978. Collage City. Second edition. Cambridge: MIT Press.

Schon, Donald. 1984. The Reflective Practitioner: How Professionals Think in Action. Basic Books.

Shirvani, Hamid. 1985. The Urban Design Process. New York: Van Nostrand Reinhold. 
Spreiregen, Paul. 1965. Urban Design: The Architecture of Towns and Cities. New York, N.Y. [etc.]: McGraw-Hill.

Sternberg, Ernest. 2000. 'An Integrative Theory of Urban Design'. Journal of the American Planning Association 66 (3):265-78.

Tibbalds, Francis. 2000. Making People Friendly Towns: Improving the Public Environment in Town and Cities. Taylor \& Francis; New edition edition.

Tonkiss, Fran. 2005. Space, the City and Social Theory: Social Relations and Urban Forms. Cambridge ; Malden, MA: Polity.

Venturi, Robert. 1977. Complexity and Contradiction in Architecture. $2 \mathrm{~d}$ ed. The Museum of Modern Art Papers on Architecture. New York: Boston: Museum of Modern Art ; distributed by New York Graphic Society.

Venturi, Robert, Denise Scott Brown, and Steven Izenour. 2000. Learning from Las Vegas: The Forgotten Symbolism of Architectural Form. 17th print. Cambridge, Mass.: The MIT Press.

Zucker, Paul. 1970. Town and Square, from the Agora to the Village Green. 1st M.I.T. Press paperback ed. Cambridge: M.I.T. Press. 